\title{
Recepción teológica de Auschwitz
}

\author{
RUBEN STERNSCHEIN y JOSÉ MARÍA MARDONES
}

\section{TEOLOGÍA JUDÍA}

\section{Sistemas de teología del Holocausto Caracterización, esquematización y ejemplos Por Ruben Sternschein}

\section{La mera pregunta}

Se plantea ante todo la justificación de la formulación del título. ¿Acaso el Holocausto presenta un desafío especial a la teología en general que exija una teología especifica del mismo? Desde dos extremos teológicos se responde negativamente. El primero es la ultraortodoxia judía ${ }^{1}$ el segundo una filosofía atea. La ultraortodoxia judía en su amplia mayoría se manifiesta en contra de toda especialización del Holocausto. Para sus adherentes toda tragedia surge del pecado como castigo divino. La magnitud del castigo es función de la del pecado, por lo cual desde el punto de vista del sistema teológico no se registra ninguna especialidad. Como exponente principal de la segunda negación de la unicidad del Holocausto cabe citarse a David Sidorsky en su artículo "Secular Theodicy and Historical Evidence"" en el que expresa que del punto de vista teológico la magnitud no cuenta por definición. Más aún si se acepta la propuesta moderna de que la filosofía analiza principalmente los conceptos fundamentales del lenguaje, ninguna evidencia histórica presentará ningún problema específico. El único desafío que podría registrarse ante el surgimiento del nazismo sería el de la fe en el progreso humano, en la investigación científica de la naturaleza en sí y en la razón humana.
Pero para ello, para el mismo desafío no es necesaria la magnitud del Holocausto.

El rol y status de la pregunta teológica en si, se verifica también en el debate en derredor de la denominación más adecuada para el genocidio perpetrado por los nazis hacia los judíos: los mayores opositores a la palabra Holocausto indican que su reserva se debe a que los asesinados no cumplieron con ello ninguna función teológica. No fueron ofrecidos a Dios por sus salvajes verdugos como en la antigüedad se sacrificaban animales y hasta hijos propios, para los dioses, bajo el nombre de holocaustos ${ }^{3}$. En tal caso debiéramos pensar que los nazis eran enviados divinos y cumplían funciones divinas en sus horrores inhumanos. Sin embargo, hay quienes explican que si bien desde el sitio de los nazis en sí, ellos representan seguramente la más abominable de las aberraciones humanas de la historia, desde el rol de los judíos ellos pudieron o bien pagar por sus pecados y expiarlos al morir de esa manera o bien pueden ser presentados como víctimas que con sus trágicas muertes transmitieron parte de la santidad divina, en especial en la forma en que llegaron a las mismas: humanos, sensibles y judíos pese a todas las penurias, pruebas y muerte previa a la muerte que se les impuso.

La pregunta, puede, en definitiva no ser sino la pregunta de Epicuro; Cómo es posible la existencia divina junto a la del mal. Si Dios, que por definición es Todo- 
poderoso y por ende puede evitarlo, no lo hace, entonces Dios es cómplice y por tanto no es misericordioso. Si en cambio, argüimos que no puede evitarlo entonces no es Todopoderoso. El tema es tratado en la literatura judía desde antaño pero al parecer no nos equivocaríamos si señaláramos que los teorizadores nunca pudieron imaginarse el enfrentamiento con su realidad histórica en forma tan extrema.

\section{Esquemas}

La vasta cantidad de fuentes escritas durante la shoah y de trabajos, artículos y libros posteriores a ella desde los más diversos puntos de vista, las más variadas preguntas y las diferentes categorías de análisis, vuelve quizá imprescindible la necesidad de una esquematización o al menos de parámetros que la faciliten.

En esta área cabe subrayar el valioso aporte de G. Perednik ${ }^{4}$, quien en su didáctico esquema de organización del material, propone cuatro parámetros en cuanto al tema del que se habla: Dios, el Hombre, la Relación entre ambos y La Vida; y tres tipos de posturas respecto a cada tema: la pesimista, la neutra y la optimista. Su síntesis se presenta así:

\begin{tabular}{cccc}
\hline & Actitud Pesimista & Actitud Neutra & Actitud Optimista \\
\hline Sobre la Divinidad & Castigo & Diálogo & Excepción \\
Sobre el Hombre & Muestra & Purificación & Mandamiento \\
Sobre la Relación & Ruptura & Prueba & Eclipse \\
Sobre la Vida & Detalle & Misterio & Contraste \\
\hline
\end{tabular}

La reflexión crítica ${ }^{5}$ a partir de su pionera, clara y didáctica contribución nos permite proponer caracterizaciones diversas. Un esquema podría clasificar y caracterizar a los autores por épocas (antes, durante y después del holocausto $)^{6}$ o bien por procedencias culturales, ideológicas o religiosas (ultraortodoxia, neo-ortodoxia, reforma y laicismo, en el judaísmo y teologías cristianas del Holocausto) ${ }^{7}$. Los parámetros a investigar en cada sistema y probablemente apoyarse en ellos para caracterizarlos o clasificarlos, podrían ser básicamente los de Perednik, quizás con algún matiz en su definición: Dios (en donde se podría clasificar por los que fortalecieron su fe, los que la declinaron, como en el caso de J. Améry y los que propusieron un fortalecimiento de una fe renovada que surge precisamente de la rebeldía contra todo intento, incluso divino(i!), de mermarla; como puede verse -por ejemplo- en algunos escritos de E. Wiesel y en el famoso "Llamado a Dios de Iossl Rakover" de Tzvi Kolitz.

Sin embargo, los estudios ${ }^{8}$ realizados sobre sobrevivientes del Holocausto muestran que en la mayoría de los casos no se registran cambios radicales a partir de la experiencia del holocausto, sino más bien una afirmación de las posturas previas apoyadas en nuevos argumentos. El segundo parámetro sería de nuevo el hombre, a partir del cual, de nuevo se podría caracterizar por un lado a los que declinan de toda fe en su naturaleza y aun en sus posibilidades como el terrible caso de Paul Celan y de Primo Levi que optaron por quitarse la vida varios años después de sobrevivir al Holocausto precisamente por 
arribar a esa conclusión. En otro sub-grupo estarían los que presentan a sabiendas y como conclusión la salida dialéctica en la que perdura la tensión entre la fe y su negación como es el caso de Berkovits que veremos y el del poeta Adorno?.

El tercer parámetro sería el de la relación entre Dios y el Hombre que debiera incluir la posibilidad de relaciones que se modifican a lo largo de la historia y se van redefiniendo en forma dinámica, tal como veremos en el caso de Greenberg, como también relaciones que responsabilizan teológicamente a ambos o ven en ambos las víctimas.

Finalmente, proponemos como parámetro de investigación y clasificación la religión en sí. Szweid en su mera distinción en los títulos de sendos artículos, uno denominado el problema de la teodicea en el holocausto y el otro el problema de la justificación de la religión a partir del Holocausto, pone de manifiesto que no se trata de lo mismo ${ }^{10}$ : Dios puede permanecer pero un determinado concepto de religión práctica, instituciones y formas de concebir la realidad y el deber hacia lo ideal, sucumbir o dañarse y viceversa: la religión puede permanecer como foco de cohesión histórica, social, cultural, antropológica proporcionando incluso un apoyo psicomoral y existencial y la figura de Dios modificarse, dañarse e incluso desaparecer. El primero podría ser el caso de Richard Rubinstein ${ }^{11}$. El segundo, de algún modo es el de Greenberg que veremos más adelante. Szweid los ve por épocas y siempre situados más bien en las posturas más tradicionales a saber el primero en el martirologio judío medieval y el segundo en los casos mentados ${ }^{12}$ junto a otros ejemplos del mundo neo-ortodoxo ${ }^{13}$ y libera ${ }^{14}$ en los que el Holocausto conlleva un cambio de actitud radical respecto a las concepciones nacionales derivadas de las religiosas, que redundó en un vuelco hacia el sionismo, como activismo histórico.
Las preguntas que habrían de explorarse en los cuatro parámetros serían de cuatro tipos:

a) La pregunta funcional: ¿Qué rol desempeñaron? ¿Qué sitio de responsabilidad les cupo en el holocausto?;

b) la pregunta moral: ¿Cómo lo permitieron?, ¿De qué modo puede justificarse o al menos explicarse su actitud?;

c) La pregunta esencial: ¿Qué son (Dios, el Hombre, la Relación, y la Religión, y de algún modo la Historia), a la luz del holocausto? ¿Cómo han de concebirse o definirse?;

d) La pregunta teológica: ¿Qué propuesta, mensaje, mandamiento ${ }^{15}$ o legado dejan a la era post-Holocausto?

\section{El Sistema de Eliezer Berkovits: un paradigma}

Escogemos el sistema de Eliezer Berkovits ${ }^{16}$ por ser paradigmático. Si bien se presenta con preguntas radicales, las respuestas son conservadoras y contienen de algún modo casi todos los elementos de las teologías judías tradicionales y muchos de la mayoría de las del Holocausto, excepto el denominado mipné jataenu (por causa de nuestros pecados) $)^{17}$.

Si nos apoyamos en los parámetros propuestos y en sus preguntas, en el caso de Berkovits es menester comenzar por "El Hombre". Ante todo porque él mismo comienza explorando a quién le es lícito formular preguntas y cuáles son moralmente válidas, $\mathrm{y}$ existencialmente auténticas. Asimismo hemos de comenzar por el hombre porque la teología de Berkovits es una teología antropológica o al menos antropocéntrica. Su pregunta teológica es “¿dónde estuvo el hombre?" y no "idónde estuvo Dios?". ¿Qué es el hombre luego del Holocausto? y si puede tenerse fe en él después del mismo.

En Berkovits se distinguen en el concepto hombre diversas aplicaciones. 
Esquemáticamente podríamos agruparlas en cuatro: a) Las víctimas, b) los victimarios, c) los cómplices en silencio, en pasividad, en teologías, filosofías y morales erróneas y d) los "hermanos de Job".

Las víctimas son concebidas en todas sus actitudes como sagradas. Salvo la actitud de los Kapos y de los líderes de los llamados Judenrate, cuyas actitudes son calificadas como normales, todas las demás son valoradas como suprahumanas o sacras: La de quienes tuvieron el valor de defenderse en un levantamiento armado sin ninguna posibilidad de éxito, la de quienes pudiendo salvarse, renunciaron a hacerlo en aras de quedarse acompañando moral y espiritualmente a hijos, esposas, alumnos, pacientes, y comunidades religiosas (en el caso de maestros y rabinos), la de quienes en medio de los tormentos no olvidaron de apiadarse de animales que dependían de ellos para alimentarse, la de quienes pudieron matar nazis aún en defensa propia y se abstuvieron de hacerlo para permanecer humanos; la de quienes pese a la trágica realidad y a las limitadísimas condiciones, encontraron motivos para continuar con la practica de tradiciones que cantan a la vida, como por ejemplo las tres comidas del Shabat y sus respectivas oraciones y canciones, la de quienes arriesgaban sus vidas para continuar ejerciendo sus facultades humanas por medio del estudio y enseñanza clandestinos del hebreo y los textos judaicos, la de quienes se suicidaron antes de caer presa de los asesinos para no morir en sus manos sino por elección libre o bien para no permitirles denigrarlos más aún y, finalmente, la de quienes simplemente hicieron todo lo posible por permanecer con vida (esconderse, mentir, fingir, comer) puesto que en esas circunstancias encontrar un motivo para escoger la vida resulta heroico.

Los victimarios representan la expresión pero de las miserias a la que puede llegar el ser humano. Ellos son definidos a su vez como los Hijos de la Historia del Poder a diferencia de los Hijos de la Historia del Espíritu (sobre lo que volveremos más adelante, en nuestro tratamiento de la relación entre Dios y el Hombre).

Los cómplices no son directamene incluidos en uno o el otro grupo mentado, si bien quedan prácticamente adjudicados a la Historia del Poder por desentenderse de toda responsabilidad.

Finalmente los descendientes de las víctimas o simplemente judíos que no lo fueron, son considerados Los Hermanos de Job. No son como sus "amigos" que lo culparon por el mero hecho de sufrir, arguyendo que no hay sufrimiento sin culpa, por lo tanto algo habrá hecho para merecerlo; sino que representan un personaje desconocido en el libro de Job: sus hermanos. Supuestamente sufren con y por él pero jamás como él. Recibieron una "herencia de perplejidad que confunde y embaraza" puesto que no pueden seguir creyendo como si nada hubiera ocurrido, en honor a quienes perdieron la fe luego de sobrevivir al holocausto. Pero igualmente no pueden dejar de creer, puesto que existen quienes lo sobrevivieron y continuaron creyendo.

A esta altura hemos de retornar a Dios. Su parte en el Holocausto, en Berkovits, se resume en demostrar su valor al permanecer pasivo en aras de la libertad del hombre. Si hubiera intervenido directamente habría atentado contra ella. La habría violado. En cambio, por no hacerlo, Berkovits no lo juzga como cómplice sino como víctima del libre albedrío humano $^{18}$.

Hasta aquí en cuanto a la pregunta funcional esencial y moral de Dios y del Hombre. Nos resta examinar el caso de la relación entre ambos, el de la Religión y verificar la pregunta teleológica en los cuatro parametros.

Berkovits no se ocupa directamente de estos últimos dos parametros aunque pue- 
de deducirse de sus textos lo siguiente: La relación entre Dios y el Hombre depende principalmente del Hombre. Como la Historia en general. Asi, los "Hijos del Espíritu" escogen vivir en una relación constante y fluída con Dios y los del Poder no. Con todo, el pueblo judío cumple su función de Pueblo-Testigo precisamente al ser pequeño y débil y aún así sobrevivir siempre. Su mera existencia testimonia la de Dios y al de la victoria de la Historia del Espíritu sobre la de la Fuerza. El mandamiento o legado consiste en incorporarse a la Historia del Espíritu, a sus valores y concepciones, antes de que hayamos acabado con todo. Berkovits aún aquí opta por un lenguaje ambiguo: La amenaza es cada vez más grande porque la fuerza (bélica) aumenta, mas también la esperanza crece en virtud de señales como la desaparición del comunismo, los límites del sueño liberal que exigen cierto control , las democratizaciones, y la creación del Estado de Israel tan cerca del Holocausto.

\section{El sistema de Greenberg: la cúspide de las dialécticas}

Irving Greenberg detalla su teología del Holocausto en varios artículos similares. Nos basamos principalmente en el denominado The Third Great Cycle in Jewish History $^{19}$.

El principio fundamental y tal vez el mayor aporte de Greenberg es la premisa de que la relación de Dios con el hombre a lo largo de la historia es dinámica, cambiante. Puede establecerse pues que en la época bíblica había mayor o menor libre albedrío mayor o menor intervención divina, mayor o menor conocimiento del hombre por parte de Dios, y viceversa. De ahí que también la definición de la esencia de cada uno, varía en el tiempo, como también la responsabilidad moral y con ello el rol teológico.
Greenberg divide la historia judía en tres grandes periodos. Cada uno esta caracterizado por un evento dramático que fija el concepto de Dios, del hombre, de la relación entre ambos, de la religión, de las instituciones judías y a su vez en cada período específico se crea un texto fundacional. Cada período nos posiciona más adelante respecto a nuestro destino mesiánico. Para Greenberg Dios le habla al mundo a través de la historia judía puesto que Israel es el pueblo testigo tal como lo establece el profeta Isaías. En el judaísmo la teología y la sociología están siempre emparentadas, una se manifiesta en la otra en constante interdependencia.

El primero es el período bíblico. $\mathrm{Su}$ evento: el Éxodo de Egipto conectado con la entrega de la Torá en Sinai. El texto es la Biblia. Dios es el Hacedor de la historia, principal protagonista activo, siempre presente y cercano, con un mensaje concreto y claro Él es la garantía del destino mesiánico. El hombre está en la tierra para cumplir a rajatabla sus mandamientos y propagarlos y en virtud de ello es juzgado, premiado o castigado. La relación entre ambos tiene un tiempo y un espacio definidos como también una tarea muy concreta. Se trata del culto en el templo. Las instituciones de liderazgo son los profetas, los reyes y los sacerdotes si bien los primeros son sus verdaderos mensajeros.

El segundo es el período que denomina "Rabínico". El evento fundacional es la destrucción del Templo y la salida a la Diáspora, al contacto directo con el Helenismo. El texto es el Talmud. La esencia Divina y humana y su consiguiente relación definitoria de la religión, se basa en un repliegue de la divinidad. Dios reduce su presencia pero exclusivamente en cuanto a su protagonismo. No se retira del mundo, se esconde precisamente en él. Y para ello sale del Santuario o Gran Templo. Ahora se encontrará en la Sinagoga que en hebreo se llama Beit Kneset o Lugar de Reunión 
y Asamblea Pero también se denomina Beit Midrash o Casa de Estudio y Bet Tefila o Casa de Oración, puesto que cumple las tres funciones a la vez: la materialización del pensamiento, del sentimiento y de la acción práctico política. La Ley Judía, Halajá, ahora lo abarca todo cada trozo de su vida, de su hacer de su sentir. Por lo tanto estará también en la mesa que come según los preceptos, bendiciones y moral de la ética judía, en la cabecera de la cama de un enfermo, en la visita del Justo, en la plegaria pronunciada con genuino sentimiento, en el amor de la pareja, en el estudio de las sagradas escrituras. Dios se esconde de la historia en general pero en el hombre en particular. Dios se oculta y se acerca más, se vuelve más íntimo en su contacto. Lo hace en un acto de amor y de fe en el hombre por medio del cual le otorga más libertad y mayor responsabilidad.

El tercer período que no se consumó como tal pese a que en un principio sus contemporáneos así lo creyeron fue el de la Emancipación. Todo lo que pareció prometer se reveló finalmente como una falacia y su derrotero fue el verdadero tercer período o ciclo. Su evento es doble, compuesto por dos partes o aspectos o etapas. Uno trágico y destructivo y el otro reparador y alentador. Ambos, insistimos, son tratados como los componentes de una sola etapa. Greenberg se refiere al Holocausto y al nacimiento del Estado de Israel. Dios en este período está más oculto aún. Y por lo tanto en más sitios de lo mundano. Se trata de una secularización total de lo sagrado. No en el sentido de su anulación, sino, por el contrario, con la intención de su difusión. Dios esta ahora no solo en el cumplimiento de los preceptos, ni en las sinagogas ni en las sagradas escrituras sino en cada acto en el cual se sepa convocarlo o, mejor, encontrarlo. En un bosque, en un atardecer, en una melodía, y aún en un autobús. En el uso reivindicador y creativo del hebreo ${ }^{20}$. Dios estuvo en el Holocausto. Luchando sufriendo, atendiendo búsquedas, esperando, escogiendo la vida y muriendo con los mártires. Si no lo detuvo, señal de que gritaba al hombre que lo hiciera. Con su mero silencio. El hombre en este período es más libre aún, más responsable aún, más activo aún. La relación entre ambos, y la religión son más silenciosas, más seculares, más abiertas a cada acto y a cada sitio. No tienen verbo sino acción. Y ahí en la acción radica el mandamiento o legado: hacer justicia y equidad, escoger -pese a todo y con renovada fe- concebir hijos, apostar a la vida cuidarla y defenderla por medio de una economía y sociedad justa e incluso por medio de un ejercito de defensa como el israelí, cobijar refugiados o desplazados (judíos o no), son algunas de las maneras de procurar y hallar lo sacro oculto en lo secular. Así se revive a Dios, precisamente al buscarlo fuera de la Sinagoga. Puesto que Israel es el escenario principal donde todo esto tiene lugar, vivir en Israel, protegerlo, defender sus derechos y oportunidades, "sionizarse" y dignificarse como judío por doquier, son formas prácticas de cumplir con el mentado legado.

En este período Greenberg no señala un texto en especial sino que indica la introducción de textos sagrados en el arte moderno israelí, y apunta diversas alusiones a lo sagrado en filmes, dramas y poemas como prueba de su caracterización como la sacralidad escondida en la secularidad.

\section{Observaciones e impresiones personales}

Ante todo he de adoptar el lenguaje dialéctico de Greenberg y de los "hermanos de Job" de Berkovits siendo hijo de sobrevivientes y rabino por un lado y pretendiendo, por el otro, estudiar la teología y la filosofía después del Holocausto y con 
alguna sistematización académica. Gracias a ellos puedo decir que en mi condición rabínica y de sobreviviente no tengo más que la perplejidad y el silencio para ofrecer junto a la asunción del desafío presentado por el Holocausto a toda fe. Yo agregaría a Heschel ${ }^{21}$ que no solo Dios es inefable sino también y tal vez más aun la fe en Él y la relación con Él. Se trata de una fe y una religión sin pruebas que no puede demostrarse y sin embargo no resulta más fácil aún abandonarlas. Ni a la razón, ni al espíritu. Podríamos consolarnos con Telushkin $^{22}$ y decir que el creyente tiene problemas con el mal pero el ateo con el bien. Propondría después del Holocausto una fe de misterios, sin justificaciones como la mencionada o bien una dialéctica en tensión o bien una del estilo de M. Kaplan, que ve en Dios la forma ideal de cada uno de nuestros valores personales y desde ahí nos juzga en lo más recóndito de nuestras capacidades en cada situación. No más un dios de la historia, de Providencia-presencia general sino más bien una instancia profundamente intima de relación personal y existencia trascendental cuya función es principalmente existencial y terapéutica. En cuanto al hombre, recojo la dificultad de la fe en Él, de Paul
Celan que en uno de sus poemas pone en su boca el grito "Rezamos" según el cual el hombre pide ser digno de que alguien no solo rece por él sino que rece a Él con merecida fe. También me identifico con la exigencia de Adorno de fijar al Holocausto como tribunal ante cada obra humano que quiera realizarse luego de Él. Finalmente subrayo con Berkovits el contraste extremo que tuvo lugar en el Holocausto entre lo más sublime y lo más bajo de lo Humano. Uno nos refuerza la fe y la esperanza y el otro nos las derrumba y entierra.

Retomo pues la sensación de tensión dialéctica de Greenberg, el grito de Tzvi Kolitz-Iossi Rakover que resuenan la fe en el sentido aún si para ello hubiera que sobreponerse o desafiar al propio Dios. Retomo la necesidad de una teología antropocéntrica por el misterio de lo divino y porque el Holocausto, a diferencia de Job fue realizado por el hombre, sin duda. Retomo pues el escepticismo de Celan, que no deja de buscar aún con su suicidio, la exigencia de juicio constante de Adorno que nos permite volver a creer para crear, y la dicotomía esperanzadora al fin de Berkovits.

\section{NOTAS}

1 Para un estudio detallado de la absoluta mayoría de los textos ultraortodoxos véanse los compendios de artículos, sermones y sentencias rabínicas siguientes: (en hebreo), I Shwartz e I. Goldstein (Editores) Hashoa, Jerusalén, 1987 y (en inglés) N. Wolpin (Editor), A Path Through the Ashes, N.Y., 1986, y también el trabajo (en hebreo) de Eliezer Szweid, Ben Jurban Lieshuá,, Jerusalén, 1990. Sin embargo existieron las notorias excepciones en casos de ultraortodoxos que identificaron al Holocausto como un caso tan especial que lo señalaron como la causa de cambios de actitud radicales a favor del sionismo, por ejemplo. El caso del Rabino Isajar Shelomó Teichtal, autor de Em Habanim Semejá (Budapest 1943, N.Y. 1969) es el más contundente si bien se registran casos de menor ortodoxia y antisionismo que en el umbral del holocausto se expresaron a favor del mismo de una forma $\mathrm{u}$ otra como lo son el Dr. Natan Birnbaum (1864-1937), el Dr.Itzjak Breuer (1883-1946) y el escritor Hilel tzeitlin (1871-1942).

${ }^{2}$ En la revista Holocaust and Genocide Studies, vol. 1, n.2, pp. 265-277.

3 Véase entre otros Emil Fackenheim, "Holocaust", en Contemporary Jewish Religious Thought, o en A Gide To Jewish Theology, A. Cohen y P. Mendes-Flohr (editores), Scribner's sons, N.Y.1987. Un argumento similar con algunas diferencias en sus fundamentos y con un desarrollo más exhaustivo puede encontrarse en Szweid, "Haim Hashoa hu erua jasar takdim?" (en Hebreo), en Maavak Ad Shajar, Hakibutz hameuchad, 
1990, 1996 que fue traducido al inglés bajo el nombre Wrestling Until Daybreak y editado por la University Press of America.

${ }^{4}$ Véase "Teología del Holocausto", en Hebreo Soy, Editorial Milá, Buenos Aires, vol. 1, pp. 237-250. Perednik propone cuatro parámetros en cuanto al tema del que se habla: Dios, el Hombre, la Relación entre ambos y La Vida y tres tipos de posturas respecto a cada tema: la pesimista, la neutra y la optimista.

${ }^{5}$ Como todo trabajo innovador, también el de Perednik crea la posibilidad de revisiones y retoques. La primera observación sería la posible desintegración de algunos sistemas en al esquema propuesto. Berkovitch, por ejemplo, cuyo sistema expondremos más adelante, podría sostener las tres posturas respecto al Hombre y ninguna respecto a Dios (puesto que para él, Dios fue víctima también). La segunda observación es el alcance o definición de los términos, puesto que el eclipse, el contraste, el misterio y el mandamiento pueden ser formas de "diálogo" o "pruebas" también, tal como fueron entendidas en la literatura rabínica antigua y medieval. (También la prueba podría ser una forma de diálogo) La participación divina denominada "diálogo" podría aplicarse tanto al Dios que hace la historia, incluido el holocausto, como -con Berkovitsal que sufre y acompaña en ella. El concepto "muestra" puede aplicarse de formas opuestas respecto al hombre, con connotación positiva en el caso de los judíos y negativa en el caso de los nazis y sus colaboradores. Por otra parte nos resulta difícil sostener la consistencia de la "excepción", tratándose de Dios y en cuanto a Job, único supuesto representante de la misma, lo vemos más cerca de la prueba, al menos en cuanto al texto en general sino en cuanto a las palabras del personaje en un determinado momento. Básicamente Job reclama el sentido de su sufrimiento, el objeto, si bien no la justicia. Finalmente si bien el esquema, insistimos, es sumamente esclarecedor, algunos sistemas no quedan plenamente aprehendidos dentro del mismo mientras que algunas opiniones marginales o extra-holocausto, son las únicas representantes de posturas bien especificadas. Probablemente Perednik pretendiera proponer más bien un esquema teórico (tal vez apoyado en ciertas posturas generales y partes de otras específicamente elaboradas respecto al holocausto) de tipos de abordaje a la teología del holocausto, que una forma de ordenar y clasificar todas las posturas existentes ad hoc.

${ }^{6}$ Por "antes" nos referimos a teologías de las catástrofes extraholocausto como a modificaciones teologico-políticas que surgen en el umbral de la Shoah como la mentada del Dr. Natan Birnbaum (ver nota 1). Por "durante" nos referimos a la mayoría de los textos comprendidos en el HaShoah mentado (ver nota 1) como también al texto del Rabino Techtal, op. cit., y al del Rabino Reformista Leo Baeck (líder de la judería alemana durante el holocausto), titulado Dises Volk, Frankfurt am Mein 1955 escrito en Tereisenstaat.
Sobre la primera, ver nota 1 . Sobre la segunda trataremos dos de los principales exponentes más adelante: el caso de E. Berkovits y el de I Greenberg. La tercera podría encontrar exponentes en los trabajos de Hescehl, Buber, y el mentado Leo Baeck los cuales se caracterizan todos por un cuasi silencio. Para la teología cristiana cfr. H.J Cargas (ed.), When God and Man Failed, N.Y. 1981; E. Fleischner (ed.) Auschwitz: The Beginning of a New Era?; N.Y. 1977; M.D. Dayan, Human Responses to The Holocaust; N.Y. 1980; H. Friedlander \& S Milton (editores) The Holocaust, N.Y. 1980.

${ }^{8}$ Cfr. Brenner, Faith and Doubt of Holocaust Survivors, N.Y. -London, 1980.

${ }^{9}$ Luego de establecer que no hay lugar para el lenguaje después del Holocausto ni para el arte ni para la ciencia ni para la filosofía por que los nazis hicieron uso de ellas, las comprendieron y se sensibilizaron con sus formas y contenidos y aún así todo ello no les represento freno alguno para sus horrores, les da una salida exigiendo a todas estas disciplinas ver en el Holocausto un desafío, un tribunal que debe enfrentarse con éxito para ganarse el derecho a existir como producciones humanas.

${ }^{10}$ Szweid establece que en determinadas circunstancias, cuando no resta alternativa más que la entrega a la muerte a quienes pretendieron continuar con su identidad religiosa, y lo hicieron, la religión que era suficientemente fuerte en su autoridad debía salir en defensa de la imagen dañada del Dios que "ocultó su rostro". Análogamente cuando supuestamente los perpetradores del Holocausto en sus horrores son vistos como castigo divino a quienes sí siguieron su camino, es el dios mismo el que tiene que salir en defensa de la imagen dañada de la religión.

${ }^{11}$ En After Auschwitz, Indianapolis, N.Y. 1966, R. Rubinstein establece que las religiones occidentales son la base de la insensibilidad moderna puesto que a la inversa del paganismo separaron la divinidad de lo terrenal. Con ello, abandonaron la sacralidad de la vida en las manos del salvajismo del que el hombre es capaz. Las religiones bíblicas son las causantes del proceso de secularización de lo terrenal y lo que conlleva su desvalorización. La trascendencia de lo divino le quitó sacralidad a la vida aquí abajo y creo la posibilidad de corromperla y destruirla. Dios, pues existe y esta ileso del Holocausto. Pero la religión murió.

${ }^{12}$ Cfr. nota 1.

${ }^{13}$ Szweid señala el caso de Irving Greenberg y de E.Berkovits entre otros que centralizan su teología del Holocausto en el Sionismo uno (el último) como muestra de los ritmos de Dios y de los diversos tipos de hombre y de Historia y el otro como la función religiosa que le toca desarrollar en esta era de máxima secularización de lo divino al judío. Cfr. más adelante.

${ }^{14}$ Se refiere a señales sionistas algo difusas en sí pero considerablemente significativas en cuanto a sus respectivos contextos culturales y religiosos de Franz Rosenzweig, y Max Winer (en diarios y corresponden- 
cias personales) y Leo Baeck (en la notoria diferencia o desarrollo desde su primer volumen preholocausto: Das Wessen des Judentums de 1905 y su segundo, post holocausto, Dieses Volk (1955) en el cual se denota una identificación nacional y una clara tendencia hacia el pensamiento sionista.

${ }^{15}$ Emil Fackenheim, sobreviviente del Holocausto luego de dos décadas de desarrollo de su propio sistema de pensamiento filosófico y teológico aborda la religión y el Holocausto y a su luz rebatió su propio sistema proponiendo un mandamiento adicional a la lista de los 613 de la tradición judaica convencional. También Berkovits y Greenberg concluyen sus trabajos con tareas existenciales o imperativos religioso novedosos.

${ }^{16}$ Faith After The Holocaust, Ktav Publishing House, Inc., N.Y., 1973.

${ }^{17}$ Cita de la liturgia judía especial para los sábados por la mañana que se utiliza por extensión para aludir a las teologías que argumentan el castigo divino ante toda catástrofe.

${ }_{18}$ Hemos de señalar que este es uno de los puntos menos consistentes de Berekovits puesto que a lo largo del libro y de otros escritos menciona la Creación del estado de Israel como parte de la intervención divina. Mas aún, como prueba de que su rol en la Historia no cesa y tarde o temprano se revela...

${ }^{19}$ En "Perspectives", National Jewish Resource Center, N. Y., 1981, pp. 1-43. Cfr. también: “Cloud of Smoke, Pillar of Fire, Judaism, Christianity and Modernity after the Holocaust" en, E. Fleischner (ed), Auschwitz: The Beginning of a New Era?, N.Y., 1977, pp. 7-57.

${ }^{20}$ Existe una opinión muy distinta, basada en un estudio exhaustivo de textos e impresiones de quienes vivían en la tierra de Israel y quienes preferían precisamente no hacerlo para mantener esa sensación de sacralidad frente a todo lo ligado a la tierra, al hebreo, a los lugares sagrados. Cfr. Ravitzky, Jerut al Halujot, Am Oved, Tel Aviv 1999, Capitulo 1.

${ }^{21}$ Cfr. El Hombre no está solo, Ediciones Seminario Rabínico Latinoamericano, Buenos Aires, 1980 y Dios en Busca del Hombre, Ibidem.

${ }^{22}$ Cfr. Ocho preguntas sobre Judaísmo, Ediciones Seminario Rabínico Latinoamericano, Buenos Aires, 1978, cuarta pregunta sobre el ateísmo.

\section{TEOLOGÍA CRISTIANA}

\section{Interpelaciones del Holocausto al cristianismo \\ Por J. M. Mardones}

J.B.Metz (1990, 103) y J.Moltmann (1997, 165) se han preguntado con frecuencia por qué la teología cristiana se ha cuestionado tan poco o nada acerca de la Shoah o Catástrofe, como también acerca de la historia de sufrimiento del ser humano. La respuesta es todo un juicio crítico a la a-patía e idealismo de dicha teología. Incluso el mismo Metz $(1996,8)$, sólo se hará consciente lentamente de la importancia de Auschwitz, de la catástrofe del Holocausto, para la teología. El inicio de una inquietud que llega a hacer de Auschwitz la medida de todo pensamiento teológico, coincide con un giro en la pregunta teológica sobre el mal. Se pasa de preguntar ¿"por qué el mal en un mundo creado por Dios"?, a $i$ "por qué el sufrimiento e injusticia de las víctimas inocentes"? Supone una mirada ético-política sobre la realidad histórica que emplaza al Dios de los fundamentos metafísicos o teológicos de la verdad, la bondad y la belleza, pero que no deja intocada la cruz de Cristo ni a las víctimas $\mathrm{y}$ verdugos mismos.

El planteamiento e inquietud de Metz ha prendido en otros teólogos cristianos, especialmente los denominados "teólogos políticos". Desde el momento que la pregunta sobre las víctimas se confronta con un Dios que las recuerda y las hace justicia, todo cambia en el pensamiento teológico: Dios, Cristo y las víctimas y verdugos. Y se pasa de un cristianismo pretendidamente inocente frente al Holocausto a reconocer que le afecta profundamente, ya que: 1) la institución, la teología y la religiosidad cristianas propiciaron la mayor parte de los estereotipos antisemitas; 2) fue una sociedad mayoritariamente cristiana la que asistió indiferente al asesinato de millones de judíos; 3) el genocidio judío fue llevado a cabo por un mesianismo político -"una suerte de herejía judeo cristiana, dirá 
R.Rubenstein (1996)- que intentaba la muerte del Dios de Abraham, Isaac y Jacob”, el Dios de Jesús.

\section{La pregunta por Dios}

\subsection{Auschwitz plantea un gran interro-} gante a Dios. Pero del modo como se pregunte depende ya una precomprensión de Dios. Moltmann $(1996,157)$ señala atinadamente que las cuestiones que comienzan con un "por qué" ("ipor qué Dios ha permitido...?", etc) son las preguntas de la teodicea, preguntas del "espectador" ante los hechos: son interrogantes teóricos que no se implican en el problema y presuponen un Dios frío, alejado y ciego frente a la Catástrofe y cualquier sufrimiento humano. Estas preguntas son falsas o sin salida; dejan a Dios y al mundo separados y buscan justificar al Dios omnipotente y bondadoso frente al sufrimiento de las víctimas inocentes.

La pregunta del implicado y sufriente, del participante, es de otro tenor: "Dios mío, por qué..." o bien, "Dios mío, dónde estabas cuando.." Preguntas quizá sin respuesta pero cuestiones permanentes que no dejan intocado ni al creyente ni a Dios. El Dios presupuesto aquí es un Dios no apático ni desentendido del mundo sino preocupado y participante de nuestro sufrimiento.

Todavía hay otra cuestión que queda sutilmente excluida si seguimos el camino de la teodicea: es el interrogante de Dios al hombre, al autor y causante de la muerte y el sufrimiento. Puede adquirir la forma del bíblico "Adam, ¿dónde estás"?, o el de "Caín, ¿dónde está tu hermano"?, o simplemente, la pregunta de S.Wiesenthal, ¿"hay reconciliación para los culpables"?

1.2. La teología cristiana que se enfrenta con el hecho del Holocausto ya no permanece igual. Como dice expresi- vamente Metz "despues de Auschwitz ya no volvemos solos, sino conjuntamente con las víctimas" (1979, 144). Esta compañía nos impele a hablar de Dios de otra manera.

Metz y Moltmann respondieron pronto ante la adorniana imposibilidad de hacer poesía o seguir orando, que era posible porque lo mismo que había habido poesía (P.Celan, y Nelly Sachs) en Auschwitz se había rezado y entonado el "Shema Israel" y el Padrenuestro. Se podía orar después de Auschwitz porque se había orado en Auschwitz. Pero la teología de la historia queda hecha trizas. No hay justificación teodiceica para un Dios señor de la historia. Los triunfadores de la historia, los todopoderosos, permanecen lejos y apáticos frente a las víctimas de la historia y del sufrimiento injusto. Hitler también invocaba al "Todopoderoso" (Der Allmächtige). Hay que sospechar de un divinidad que todo lo determina y no es determinado por nada ni nadie. ¿Dónde estaba el Señor que todo lo gobierna,...en Auschwitz?

D.Bonhöffer recordaba ya en 1944 que "sólo un Dios sufriente nos puede ayudar". Siguiendo la estela bíblica remitía a responder a "un Dios sufriente que nos llama a participar de este sufrimiento en un mundo sin rastro de Dios". La solidaridad con las víctimas es la respuesta consecuente de la fe para Bonhöffer (1942: Timo Peters, 1995, 18s.). Ya A. North Whitehead en 1929, tras la muerte en accidente de su hijo de 21 años, decía en su metafísica que "God is the great companion -the fellowsufferer who understand" $(1929,532)$. Esta senda tiene sus grandes antecedentes en la "Schekina" judía que hace "habitar a Dios en medio del pueblo de Israel" y le acompaña al exilio en la ocultación ("hester panim") y la autohumillación, y en la Cábala española de Isaak Luria que desarrolló la idea ("Zimzum") de un Dios que se autolimita, oculta y autohumilla 
para dejar sitio a la creación y, especialmente a la libertad humana. La cristología de Lutero que lleva al paradójico ocultamiento de Dios en la manifestación en Jesucristo (E.Jüngel, 1986, 265-75), sigue este camino. Dios, por tanto, se ha autolimitado, autokénosis, por amor a sus criaturas. No es que ha dejado de ser omnipotente y ahora tengamos un Dios débil e incapaz de salvarnos (Metz, 1996, 19), sino que su omnipotencia no es un absoluto intocable, sino una omnipotencia situada, concreta y comprometida (Torres Queiruga, 2000, 205s. ). El amor que es Dios y que se da sin retener, da el don de la libertad a otros, a fin de que respondan libre y responsablemente con amor. Ahora bien, la libertad finita tiene la posibilidad no sólo de la acogida, sino también del rechazo $\mathrm{y}$, por consiguiente, del mal pervirtiendo la gratuidad del don del bien (Scannone, 2000, 299).

Hay que reconocer, con todo, que J.B. Metz (1996, 20s), siguiendo a K.Rahner (1982, 245s), pone el dedo en la llaga cuando sospecha de una duplicación e impotencia humanas y hasta estetización del sufrimiento cuando hablamos del Dios que sufre. Descubrimos que el Holocausto, el sufrimiento de las víctimas, cuestiona radicalmente nuestro hablar "sobre" Dios. El suspiro de la criatura oprimida se niega a dejarse consolar por ideas o mitos.

Pero, al menos, una cosa está clara: el Dios todopoderoso Señor de la Historia que mira impasible o como juez ya no es soportable ni creíble, murió en Auschwitz. Será, en todo caso, un Dios "poderoso en el callar" y por eso escondido cuando no autolimitado. Un Dios que ahora nos necesita a nosotros que diría H.Jonas (1998, 250s) siguiendo la intuición experiencial de E. Hillesum (1989); un Dios que respeta nuestra libertad y por ello deja el mundo en nuestras manos. Un Dios que al crear un mundo finito no puede crear y mantener un mundo sin mal (Torres Queiruga,
2000, 206). ¿Por qué entonces, mi Dios, creaste este mundo donde iba a existir Auschwitz, Gulag y los desaparecidos de todas las partes del mundo? Este Dios se arriesga en el amor al confiar hasta tal punto en el hombre y su libertad. Un Dios que se arriesga por amor a sus criaturas y se identifica con las víctimas (Mt. 25, 35) podemos pensar, está con y en las víctimas (E. Wiesel, 1996, 121; Moltmann, 1997, 163).

1.3. El hablar sobre Dios después de Auschwitz para Metz $(1996,25)$ o "durante Ayacucho", que diría G. Gutiérrez (1988, 336), es a estilo de Jesús, el lenguaje de "una mística del sufrimiento junto a Dios". No es tanto una respuesta consoladora sobre el sufrimiento cuanto la apasionada pregunta que brota del sufrimiento y que pide aclaraciones a Dios en tensa expectativa. Es todavía mucho más que el Iosl Ráckover de Zvi Kolitz (1998, 25), el clamor de Jesús en la cruz, del que había sido abandonado por Dios pero que jamás había abandonado a Dios.

Traducido a características sobre la racionalidad, un tal habla podremos denominarlo solidario-compasivo, es decir, que auna lo ético, práctico e histórico en un sólo estilo de pensamiento.

Se advierten los límites de toda teorización, incluso teológica, sobre el sufrimiento de las víctimas inocentes con Dios al fondo o al frente: tiene que dejar sitio a la oración y la acción. La memoria de las víctimas moviliza un concepto no apático de Dios ni del creyente: la impasibilidad de la fe -y de todo concepto- conduce a unir la reflexión y la contemplación, la oración y la acción, la mística y la política.

\section{La pregunta por Cristo}

2.1. Tras Auschwitz es tan increíble un Dios todopoderoso y apático, como un 
Cristo pantocrático. Si la cristología da una respuesta rápida y triunfalista ante el sufrimiento de las víctimas hemos ganado muy poco en la teología: reaparece el Dios todopoderoso de la teodicea a través del rodeo de la cruz de Cristo. Y esto ha sucedido a menudo como para no tenerlo en cuenta. Cristo es el Dios encarnado que nos ayuda, no a través de su omnipotencia, sino a través de la impotencia (D. Sölle, 1973, 179s): aparece al lado de la víctima y él mismo víctima. Una impotencia que no es inactividad pasiva, habría que aclarar, sino que introduce un estilo nuevo de realización humana a través de la compasión solidaria efectiva con las víctimas inocentes. Este es el modo como salva Jesús en la Cruz: no a través de una presunta expiación a un Dios sádico, sino mediante la introducción de un "gen anticancerígeno" en medio de la apatía y la insolidaridad humanas, "un servicio desinteresado a la causa del hombre" (Moingt 1995, 195). Una salvación en camino, que "todavía-no" ha llegado a su plenitud. De ahí que vivamos el momento de la espera, es decir de la tensión mesiánica que quiere traducir en consecuencias intrahistóricas de liberación para los oprimidos la esperanza definitiva. La cristología que no guarda esta reserva y tensión escatológica es, como repite Metz, pura ideología de vencedores.

2.2. La Cruz de Cristo ha sido malentendida durante veinte siglos, cuando no se ha convertido, desde Constantino, en símbolo de los triunfadores y conquistadores. No ha conseguido despertar a los creyentes a la preocupación principal que impulsó a Jesús de Nazareth: no tanto el pecado de los otros, sino el sufrimiento de los otros (Metz, 1996, 26). Tampoco ha sacudido suficientemente las conciencias como para llevarles a la seriedad y profundidad del mal en el mundo, la oposición de los poderes y estructuras de pecado de este mundo que provocan la muerte en la cruz del Hijo. La cristología tiene la ocasión, después de Auschwitz, de despertar de su letargo y poner las cosas en su sitio.

2.3. Jesús de Nazareth es ante todo judío. Como expresa muy bien Moltmann $(1998,107)$ en una suerte de experimento mental, Jesús hubiese ido con su pueblo a Auschwitz, con los suyos, como Edith Stein, E. Hillesum,... Es decir, el cristianismo que no quiere saber nada del judaísmo como víctima, se queda vacío, sin Jesús. Y si Auschwitz es, como repite I.Maybaum, el símbolo de las víctimas de la "civilización cristiana”, la Cruz será su corroboración si no abraza a todas la víctimas sufrientes. La teología cristiana tiene que volver a aprender que pronunciar el nombre de Jesús no se puede hacer sin rememorar el Dios del primer Testamento, amor y justicia, tardo a la ira y rico en piedad. Es decir, en Auschwitz murió el Dios cristiano antisemita y nació la ocasión para que el verdadero Dios cristiano una su destino al del pueblo judío.

\section{La pregunta por el cristianismo}

El cristianismo, la iglesia, queda cuestionada radicalmente en Auschwitz iDónde estaba el cristianismo y las iglesias? Sabemos que hubo resistencia hasta la muerte: pastores y sacerdotes que se negaron a celebrar la eucaristía -gestos, como el del pastor K. Immer en Barmen que entró en la iglesia, fue al altar y apagó las velashubo la "iglesia confesante", pero hubo demasiado silencio, ceguera sospechosa y proclividades institucionales.

El cristianismo ha sido cuestionado tan profundamente que, como algunos pensadores judíos dicen, murió en Auschwitz. Sin duda el cristianismo que se ha creído, triunfalísticamente, heredero único de la tradición bíblica, pueblo mesiánico elegido, que sustituía a Israel y perdió la con- 
ciencia de dónde venía, este cristianismo ha muerto. "Dependemos de la historia de sufrimiento de los judíos" (Metz, 1984, 218). Ya no se puede continuar un cristianismo sin conciencia de la dimensión judía de la forma de fe cristiana. Ha muerto el cristianismo y la iglesia de las connivencias con el nacionalsocialismo y con todos los crímenes de la humanidad: el cristianismo que ha perdido su dimensión profético mesiánica de defensa del hombre pobre y la víctima y del que se yergue justificando a los poderes de este mundo. Sólo cabe el cristianismo solidario con las víctimas. El otro, no es cristianismo sino retórica religiosa.

La Catástrofe, el Holocausto, cuestiona a la iglesia tan profundamente que se puede preguntar si realmente es cristianismo o es una versión religiosa que ha suplantado la sustancia del movimiento impulsado por Jesús. Un pensamiento cristiano lúcido siempre tiene que plantearse este peligro de tergiversación mayoritaria, aunque permanezca un "resto" que permita abogar por su continuidad. Auschwitz lanza una negra sombra que prohíbe cualquier veleidad sobre la realidad del cristianismo de este tiempo y sobre todo el cristianismo. Hay una tarea de crítica ideológica y de desenmascaramiento de las distorsiones sistemáticas en las tradiciones e instituciones eclesiales.Y todo creyente se tiene que sentir interpelado: la banalidad de su vida como creyente le coimplica en las consecuencias perversas, no queridas, de este cristianismo. Hay una tarea de autocrítica y conversión.

\section{La pregunta por la víctima y el victimario}

4.1. La gran pregunta que suscita el Holocausto no sólo es ¿dónde estaba Dios o el cristianismo en Auschwitz?, sino también ¿dónde estaba el hombre en Ausch- witz? Sabemos que muchos de los supervivientes de los campos de concentración se suicidaron. No pudieron creer suficientemente en el hombre o la humanidad. Auschwitz representa la enorme vulnerabilidad del ser humano y de la humanidad, la decadencia de la solidaridad, el empequeñecimiento moral,... La historia profunda del ser humano se lee en estas catástrofes.

$\mathrm{Y}$ al mismo tiempo, como repite T.Teodorov, no se nos tiene que olvidar el entramado de condicionantes, el sistema, en el que se ejerce la libertad humana. La mayoría de los culpables no son "ni bestias ni monstruos".

4.2. La solidaridad con las víctimas no es capaz de extirpar una serie de cuestiones: ¿hay perdón para los culpables? ¿En qué condiciones? ¿Es posible la reconciliación entre las víctimas y los verdugos?

Hacer memoria de las víctimas equivale, cuando no es una repetición obsesionada del daño recibido, a sentar la bases para transformar el presente en vistas de otro futuro para los mismos criminales. El perdón es posible. Lo tiene que conceder la víctima. Pero un perdón sin justicia es un oprobio. Es decir, el perdón exige conversión. Por esta razón la justicia para los verdugos y opresores empieza por un acto de memoria honrando a las víctimas (Ch. Duquoc, 2000, 122). Y esta anmistía no puede suponer un olvido, es decir, la negación del sufrimiento de las víctimas, sino el duelo por las mismas.

Moltmann (1997, 170s) apela al Dios sufriente en Jesús de Nazareth, la incondicional solidaridad de Cristo con los oprimidos de la historia (Tück, 2000, 190) para liberar al ser humano de la carga insoportable que lo ata a su culpa inconmensurable en el pasado. El pasado rememorado ("eingedenkt") y que actualiza el duelo, proceso de conversión, libera también de la carga de la culpa y permite construir un nuevo futuro. En síntesis: la reconci- 
liación supone la justicia que a su vez exige la memoria y el juicio y éste el dolor y el duelo que produce la aceptación de la verdad y el proceso de conversión.

4.3. Aunque finalmente la justicia se imponga y los verdugos no triunfen sobre las víctimas siempre queda la cuestión de cómo lograr la reconciliación entre víctimas y culpables. El no poder perdonar de las víctimas se interpone a menudo como las heridas no cicatrizadas. No hay palabra capaz de superar este abismo. Y, sin embargo, el creyente cristiano sigue pensando que Dios ha levantada el signo de reconciliación entre los hombre en la Cruz de Cristo. En la identificación de Jesucristo con todas las víctimas se puede atisbar lo que F. Rosenzweig, comentando una poesía de Jehudá Halevi, llamó el legado del amor cristiano al enemigo: la posibilidad de afirmar a su enemigo como futuro hermano (Tück, 2000, 198).

\section{Reflexión final}

Volvemos a la cuestión inicial: ¿por qué al pensamiento teológico cristiano le ha costado tanto hacerse cargo del Holocausto? ¿Por qué los seguidores del Crucificado Resucitado son tan remisos para afrontar la historia de sufrimiento de los seres humanos?

Hay algo en la historia misma de Jesús que nos puede dar la clave de este problema: sabemos por los Evangelios mismos que la cuestión más difícil de encajar en la fe cristiana fue justamente la cruz. El Mesías ajusticiado era algo incomprensible. ¿Cómo podía ser aceptable que Dios estuviera de parte de una víctima condenada oficialmente como Jesús? Incluso los Evangelios ponen la tipología de las tres tentaciones de Jesús como un haz de negaciones de esta clase de mesías. Un aviso para la posterioridad que no ha sido jamás aprendido. Un anticipo de lo que iba a ser la historia del cristianismo: la de la permanente lucha por olvidar y recuperar la raíz de la experiencia cristiana: lo sagrado es el ser humano, especialmente el pobre, la víctima, el oprimido. Con ellos se identifica el Jesús Señor y Juez de la Historia (Mt. 25, 35).

Aquí está la tradición bíblica de la Schekiná y la Encarnación: Dios planta su tienda entre nosotros. Pero la tentación permanente es olvidarlo y colocar a Dios en el Templo, el Culto. Hay toda una estrategia de olvido de esta experiencia bíblica que adopta formas de pensamiento en "la impasibilidad del concepto", que tienen su prolongación teológica en el idealismo y la apatía frente a la historia de sufrimiento, y maneras religiosas en la juridificación y religiosización del cristianismo. Finalmente la religión, mediante su permanente "vuelta al culto", suplanta al mismo Dios y se hace centro de lo sagrado. En vez de ser el hombre pobre y víctima lo sagrado, ahora lo es el ceremonial y las prescripciones sagradas. El levita y el sacerdote pueden pasar ya de largo por delante del caído o dar un rodeo e ir al culto con buena conciencia. Tendrá que venir el hereje y de fuera del Pueblo, el samaritano, para recordar a los creyentes dónde está el centro de lo sagrado y del encuentro con Dios: en hacerse prójimo, aprojimarse al caído y la víctima (Lc. 10, 36). Una postura activa que requiere escuchar la interpelación del otro. Mientras los creyentes cristianos estén más pendientes del culto y la "religión" que de la causa del hombre, no habrán entendido nada de la tradición del Mesías Siervo de Yahvé. Y podrán hacer de la Cruz un signo victorioso de cruzadas, conquistas, pogromos o, sencillamente, de olvido del ser humano en necesidad. El Holocausto está cerca y su olvido también.

La lección y tarea para una filosofía de la religión es, por tanto, asumir el "giro histórico-práctico del recuerdo de las víc- 
timas" como motor del pensamiento. De cualquier pensamiento y, por tanto, del teológico también. Un pensamiento de este género incorpora la memoria del sufrimiento de las víctimas como interpelación permanente y abre una mirada de sospecha crítica sobre el presente, cuya hermenéutica se proyecta en apertura compasiva hacia un futuro más humano que hay que hacer teniendo siempre como criterio la justicia que demandan el sufrimiento de las víctimas. Sin este pensamiento compasivo no hay conceptos pasibles ni posibilidad de una filosofía ni teología que se haga cargo del otro caído.

\section{BIBLIOGRAFIA}

Ch. Duquoc (2000), "La memoria de las víctimas", Selecciones de Teología, vol. 39 , n. $154,118-24$.

G. Gutiérrez (1984), "Cómo hablar de Dios desde Ayacucho", Revista Latinoamericana de Teología, n. 5, 233-41; también en Concilium, 227 (1990), 131-143

Etty Hillesum (1989), Cartas desde Westerbork, Casa Baroja, San Sebastián

P. Imhoff, H. Biallowons (1982), Karl Rahner im Gespräch, München.

H. Jonas (1998), Pensar sobre Dios y otros ensayos. Herder, Barcelona

E. Jüngel (1984), "Gottesbegriff nach Auschwitz", en Gottes Zukunft-Zukunft der Welt, FS für Jürgen Moltmann, München, 265-75.

J.B. Metz (1990), "Theologie als Theodizee?", en W. Oelmüller (Hrg.), Theodizee-Gott vor Gericht? W. Fink Verlag, München, 103-118.

- (ed.) (1996), El clamor de la tierra. El problema dramático de la teodicea, Verbo Divino, Estella, 7-28.
- (1984) "Teología cristiana después de Auschwitz" Concilium, n. 195, 209-223.

- Con E. Kogon (1979), (Hg.), Gott nach Auschwitz, Herder, Frieburg.

J. Moltmann (1998), "Jesus in Auschwitz", en J. Manemann/J.B. Metz (ed.) Christologie nach Auschwitz, LIT, Münster, 104-110.

- (1997), Gott im Projekt der modernen Welt, Kaiser, Gütersloher, 155-73.

A. North Whitehead (1929), Process and Reality, New York.

J. Moingt (1995), El hombre que venía de Dios, Desclée, Bilbao vol. II.

W. Oelmüller, "No callar ante el sufrimiento. Ensayos de respuesta filosófica”, en J.B. Metz (1996), El clamor de la Tierra. El problema dramático de la teodicea, EVD, Estella, 71-87.

T.R. Peters (1995), Nach Auschwitz von Gott sprechen, Kathol. Akademie Hamburg.

R. Rubenstein (1996), After Auschwitz. Radical Theology and Modern Judaism,

J.C. Scannone (2000), "Dios desde las víctimas", en Barbosa, Casalla... et alii, Márgenes de la justicia, Altamira, Buenos Aires.

D. Sölle (1973), Leiden, Stuttgart.

A. Torres Queiruga (2000), Del Terror de Isaac al Abbá de Jesús, EVD, Estella.

J.H. Tück, (2000), “ ¿Reconciliación entre culpables y víctimas? Ensayo soteriológico a propósito de la Shoah", Selecciones de Teología, vol. 39, n. 155, 189-99.

Zvi Kolitz (1998), Iosl Rákover habla a Dios FCE, Buenos Aires, México...

E. Wiesel (1996), Todos los torrentes van a la mar. Memorias. Anaya \& Mario Muchnik, Madrid.

- (con J.B. Metz) (1996), Esperar a pesar de todo, Trotta, Madrid. 